\title{
BAIXA CONSCIÊNCIA DEMOCRÁTICA E DIREITOS SOCIAIS: QUANDO OS DIREITOS POLÍTICOS FOMENTAM NOVOS DIREITOS
}

\author{
Lázaro Alves Borges ${ }^{1}$
}

Resumo: A baixa participação política dos brasileiros aliada ao sistema de associativismo da relação das dádivas resulta na ausência de políticas públicas de caráter majoritário e fomento à corrupção. $\mathrm{O}$ artigo busca observar a relação entre direitos sociais, cidadania, corrupção e o papel dos juízes. Analisa o arcabouço normativo da Constituição que estabeleceu um maximalismo democrático. Para isso, utiliza a doutrina das dádivas de Marcel Mauss e da "inversão da lógica de Marshal" de Murilo de Carvalho. Por fim, analisa o papel de efetivação do Poder Judiciário sem que haja um despertar cívico.

Palavras-chave: Maximalismo democrático; Cidadania; Direitos Sociais; Constitucionalismo latino-americano; Poder Judiciário.

\section{LOW DEMOCRATIC CONSCIOUSNESS AND SOCIAL RIGHTS: WHEN POLITICAL RIGHTS FOSTER NEW RIGHTS}

Abstract: The low political participation of Brazilians allied to the system of associativism of the debt ratio results in the absence of public policies of major character and fomenting corruption. The article seeks to observe the relationship between social rights, citizenship and corruption and the work of the judges. It analyzes the normative framework of the Constitution that established a democratic maximalism. For this, it uses the doctrine of the gifts of Marcel Mauss and of the "inversion of the logic of Marshal" of Murilo de Carvalho. Finally, it analyzes the role of effective Judiciary without there being a civic awakening.

Keywords: Democratic maximalism; Citizenship; Social rights; Latin American constitutionalism; Judicial power.

\section{Introdução}

Os direitos são produtos históricos das lutas de grupos sociais para que determinadas demandas fossem respeitadas. A inversão axiológica de concretização de direitos do Estado para o indivíduo, resultando numa valorização da pessoa humana, concretizou novos anseios sociais. Das liberdades e direitos fundamentais à concretização

\footnotetext{
${ }^{1}$ Mestrando em Direito pela Universidade Federal de Direito. Especialista em Direito Público pela Faculdade Baiana de Direito e Gestão. Advogado.
} 
de um mínimo vital, de um único sujeito ideal à pluralidade de modelos existencial, os direitos humanos mostram-se em constante transformação.

Em obra clássica da Antropologia, Marcel Mauss traz a noção de dádiva, relação obrigacional (dar/receber/retribuir), comportamento universalizável, que cria relações comunitárias, mas que em esfera pública pode propiciar favoritismos e corrupção.

Outro marco teórico da análise é o livro "Cidadania no Brasil, um longo caminho" de José Murilo de Carvalho, buscando observar a relação entre a democracia no Brasil e a concretização de direitos básicos. O problema de pesquisa busca analisar se o incremento dos direitos políticos e na consciência de sujeito de direitos reduz as competências judiciais na concretização dos direitos, aliando os estudos brasileiros de ciências sociais ao fenômeno jurídico. Busca trazer um olhar sobre a discussão do paternalismo, do hiperpresidencialismo e do controle de políticas públicas por via do Judiciário aliada à concepção de democracia maximalista fundada na Constituição Federal de 1988. O método de pesquisa é o documental com enfoque dedutivo.

A pesquisa objetiva que as práticas judiciárias não restrinjam à postulação e ao deferimento das demandas dos cidadãos, mas expandam-se para o convencimento argumentativo e o esclarecimento de direitos básicos.

Para tanto, busca-se (1) observar as correntes políticas da democracia do minimalismo ou teoria das elites no aspecto político, ainda presente em discursos e práticas que envolvem a esfera pública; (2) analisar o maximalismo democrático como corrente adotada pela Constituição Federal de 1988, que visa à inclusão de pautas e a pluralização do direito; (3) análise antropológica de dádivas em Marcel Mauss e histórica dos direitos sociais e democracia no Brasil com base na doutrina de José Murilo de Carvalho; (4) correlacionar a baixa consciência cidadã à efetivação de direitos fundamentais e o aumento das competências jurisdicionais, dado que os cidadãos preferem socorrer-se do acesso à justiça do que o embate político nas instâncias democráticas o que implica o aumento das competências, por exemplo, do Supremo Tribunal Federal.

A ausência de cultural constitucional, que envolve trabalhar conceitos básicos como a cidadania e o pertencimento à esfera pública fomentam um elitismo político e o 
assoberbamento das instâncias judiciais. Não que se pretenda inviabilizar o acesso à justiça, mas excitar a discussão sobre o papel político do cidadão, impulsionando um ciclo contínuo de acesso a direitos e reivindicação dos órgãos competentes.

2. Minimalismo, maximalismo democrático e consciência política

Inicialmente, é interessante observar que a democracia pode ser relida em diversas correntes políticas (liberal, socialista, republicana, conservadora, dentre outras). A escolha do recorte metodológico buscou verificar quais correntes, dentre elas, numa perspectiva dicotômica, aliam-se à possibilidade de novos sujeitos constarem na dinâmica democrática de fortalecimento dos direitos sociais.

Sob um olhar fático sociológico oriundo do século XIX, o minimalismo democrático traz uma abordagem numa perspectiva da Sociologia Clássica, traduzindo numa ideia de democracia como representação e o povo como incapacitado de gerir a máquina pública. Para os teóricos elitistas (PERISSINOTO, 2009, p. 20; HOLANDA, 2001, P. 09), aplicando o método das ciências naturais, considera que a democracia é governada por uma classe política mais preparada, dividindo a sociedade em dirigentes (poucos) e governados (muitos), numa possibilidade de ascensão ocasional e difícil. Para Jaime Barreiros Neto (2017, p. 121), os regimes totalitários como fascismo e nazismo convergem ao elitismo político ao criticarem o regime democrático, indesejado perante a necessidade de estabelecimento de um poder político centralizado e forte, a ser exercido por uma elite preparada para o desafio de unificar o território nas mãos de um único governante. Todavia, delineiam uma visão realista e pessimista da sociedade, buscando uma perpetuação da rigidez entre classes.

Em oposição, a democracia contemporânea orienta-se para um maximalismo democrático, posição contrária à corrente anterior, estando positivada em diversos instrumentos jurídicos da democracia brasileira (BARREIROS NETO, 2017, p. 463). O maximalismo democrático é corrente política que visa a ampliação dos canais de participação popular e a proteção das minorias no processo democrático. A menção 
preambular expressa à sociedade fraterna, pluralista e sem preconceitos ${ }^{2}$, pluralismo político como princípio fundamental ${ }^{3}$, a própria ampliação do direito ao voto a todos os cidadãos (que somente excluiu os conscritos durante o período de serviço militar obrigatório $)^{4}$, a representação proporcional dos partidos ou dos blocos parlamentares, a liberdade partidária e os direitos à minorias parlamentares na condução da política como de constituição de Comissões Parlamentares de Inquérito ${ }^{5}$ e de constituição em órgãos representativos como Conselho da República ${ }^{6}$ em patamar constitucional reforçam esta tese.

\footnotetext{
${ }^{2}$ Segundo nosso preâmbulo, que, embora tenha força normativa mitigada, sendo tão somente vetor interpretativo conforme entendimento do Supremo Tribunal Federal, ressalta a redução da discriminação que uma maioria possa impor à minoria. Vale a pena relembrar da redação literal: "Nós, representantes do povo brasileiro, reunidos em Assembléia Nacional Constituinte para instituir um Estado Democrático, destinado a assegurar o exercício dos direitos sociais e individuais, a liberdade, a segurança, o bem-estar, o desenvolvimento, a igualdade e a justiça como valores supremos de uma sociedade fraterna, pluralista e sem preconceitos, fundada na harmonia social e comprometida, na ordem interna e internacional, com a solução pacífica das controvérsias, promulgamos, sob a proteção de Deus, a seguinte CONSTITUIÇÃO DA REPÚBLICA FEDERATIVA DO BRASIL.” (grifo nosso)
}

3، Art. $1^{\circ}$ da Constituição Federal: A República Federativa do Brasil, formada pela união indissolúvel dos Estados e Municípios e do Distrito Federal, constitui-se em Estado Democrático de Direito e tem como fundamentos: V - o pluralismo político." (grifo nosso)

${ }^{4}$ Art. 14 da Constituição Federal: A soberania popular será exercida pelo sufrágio universal e pelo voto direto e secreto, com valor igual para todos, e, nos termos da lei, mediante:

$\S 2^{\circ}$ Não podem alistar-se como eleitores os estrangeiros e, durante o período do serviço militar obrigatório, os conscritos. (grifo nosso)

5 Art. $57 \S 3^{\circ}$ da Constituição Federal: As comissões parlamentares de inquérito, que terão poderes de investigação próprios das autoridades judiciais, além de outros previstos nos regimentos das respectivas Casas, serão criadas pela Câmara dos Deputados e pelo Senado Federal, em conjunto ou separadamente, mediante requerimento de um terço de seus membros, para a apuração de fato determinado e por prazo certo, sendo suas conclusões, se for o caso, encaminhadas ao Ministério Público, para que promova a responsabilidade civil ou criminal dos infratores.

O Supremo Tribunal Federal construiu a tese de que seria um direito constitucional das minorias parlamentares "A Constituição do Brasil assegura a 1/3 dos membros da Câmara dos Deputados e a 1/3 dos membros do Senado Federal a criação da CPI, deixando, porém, ao próprio parlamento o seu destino. A garantia assegurada a 1/3 dos membros da Câmara ou do Senado estende-se aos membros das assembleias legislativas estaduais - garantia das minorias. O modelo federal de criação e instauração das CPIs constitui matéria a ser compulsoriamente observada pelas casas legislativas estaduais. A garantia da instalação da CPI independe de deliberação plenária, seja da Câmara, do Senado ou da assembleia legislativa. (...) Não há razão para a submissão do requerimento de constituição de CPI a qualquer órgão da assembleia legislativa. Os requisitos indispensáveis à criação das CPIs estão dispostos, estritamente, no art. 58 da Constituição do Brasil/1988. [ADI 3.619, rel. min. Eros Grau, j. 1º-8-2006, P, DJ de 20-4-2007.]

${ }^{6}$ Art. 89 da Constituição Federal: Art. 89. O Conselho da República é órgão superior de consulta do Presidente da República, e dele participam:

IV - os líderes da maioria e da minoria na Câmara dos Deputados;

V - os líderes da maioria e da minoria no Senado Federal; 
Em âmbito infraconstitucional, cabe ressaltar políticas públicas de acesso e ampliação da deliberação como: (1) necessidade de audiências e consultas públicas nas licitações de grande vulto (art. 39 da Lei 8666/93); (2) facultatividade de amicus curiae nos processos de aferição da compatibilidade com a Constituição Federal no âmbito do Supremo Tribunal Federal (para o controle concentrado, art. 7 §2 da Lei 9868/99 na Ação Direta de Inconstitucionalidade e art. $6^{\circ} \S 1^{\circ}$ da Lei 9882/99; para o controle difuso, o Código de Processo Civil de 2015, em seu art. 138, estabelece o amicus curiae como intervenção de terceiros), as cotas raciais em concursos públicos (Lei 12990/2014), as cotas de candidaturas das mulheres na política (art. $10 \$ 3^{\circ}$ da Lei das Eleições - Lei 9504/96), dentre outros.

Nessa corrente maximalista, há uma valorização da diversidade democrática em que a deliberação dos temas de interesse público esteja na sociedade civil. Todavia, estudos concluem que o intercâmbio entre espaço público e condições privadas tem paulatinamente distanciado - ao arrepio dos liberais -, o que faz com que sejam necessárias pautas de moralização da vida pública e de condições equânimes de espaço de deliberação. Nesse sentido, é necessário que sejam incorporadas pautas de participação e ações afirmativas dos grupos mais vulnerações pelos laços de eticidade e de modificações da esfera pública (HONNETH, 2009, P. 270; FRASER, 2012), igualando as oportunidades de convivência em comunidade.

Segundo Axel Honeth, a condição de autorrealização em sociedade, buscada por uma estima social reconhecida pelos laços jurídicos (eticidade do Direito) deve ser resguardada para que os indivíduos se vejam reconhecidos em suas capacidades e propriedades particulares. Salienta que, para além da segurança pública e proteção da integridade pessoal, o direito deve influir sobre horizontes de valores fundadores da comunidade (HONNETH, 2009, p. 270) ${ }^{7}$.

Nesse sentido, hodiernamente, Nancy Fraser pontua que "a participação significa o poder falar com voz própria e, simultaneamente, por conseguinte, poder

\footnotetext{
7 “Os padrões de reconhecimento do direito penetram o domínio interno das relações primárias, porque o indivíduo precisa ser protegido do perigo de uma violência física, inscrito estruturalmente na balança precária de toda ligação emotiva: consta das condições intersubjetivas que possibilitam hoje a integridade pessoal não somente a experiência do amor, mas também a proteção jurídica contra as lesões que podem estar associadas a ela de modo causal. Mas a relação jurídica moderna influi sobre as condições da solidariedade pelo fato de estabelecer as limitações normativas a que deve estar submetida a formação de horizontes de valores fundadores da comunidade."
} 
construir e expressar a identidade cultural própria através do idioma e estilo". Salienta ainda que "a ideia de uma sociedade multicultural somente tem sentido se supormos uma pluralidade de cenários públicos nos quais participam grupos com diversos valores e retóricas." Salienta que a sociedade é constituída por uma multiplicidade de públicos, que devem ser ouvidos e respeitados sob uma ótica de promoção.

Desse modo, observa-se que discutir democracia é trazer um conceito inacabado de condução da vida política em que os limites da condução da vida pública ao autoritarismo perpassa por uma linha tênue, que deve ter como meta a valorização do indivíduo. Particularmente, o modelo delineado pela Constituição Federal de 1988 representou um avanço civilizatório, de forma a promover canais de comunicação entre as massas, para proteção dos direitos individuais num Estado de Livre Concorrência e promoção específica dos grupos vulneráveis. Mostram-se temerárias as iniciativas de refundar o pacto político, com propostas como Nova Constituinte sob pena de recrudescimento de direitos (ABRANCHES, 2018, p. 373).

$\mathrm{O}$ espectro maximalista democrático brasileiro reforça uma divergência e pluralidade no parlamento que reflete a sociedade plural, mas ocasiona uma dificuldade de aprovação de textos normativos axiomáticos, em que não haja provocação acerca da sua constitucionalidade. A própria ideia dos instrumentos de democracia maximalista como políticas de ação afirmativa e casamento entre pessoas do mesmo sexo ainda são questionadas por segmentos liberais e conservadores da sociedade sob o manto da vontade de geral. A proteção das minorias não é tarefa fácil em que, por vezes, o Supremo Tribunal Federal é acusado de ativista, como se a única postura do Poder Judiciário fosse de resguarda a decisão normativa congressual.

Esse aspecto de inclusão das minorias no processo democrático é ressaltado por Dirley da Cunha Junior, ao enunciar um Estado Constitucional Inclusivo (CUNHA JUNIOR, 2017, p. 15), movimento presente nas Constituições Alemã de Bonn (1949), Portuguesa (1976), Espanhola (1978) e Portuguesa (1988), que busca “o cumprimento das promessas constitucionais de redução das desigualdades, de proteção de grupos vulneráveis e de inclusão social, depende da plena e integral efetividade dos direitos fundamentais sociais". A busca de um Estado Constitucional Inclusivo passa pela efetividade dos direitos sociais como uma perspectiva cidadã. 


\section{Perspectiva e fragilidade dos direitos sociais}

A temática dos direitos sociais é recorrente na doutrina brasileira. Desde a Constituição de 1988, discute-se o caráter dos direitos sociais quanto à sua eficácia jurídica e social, não havendo consenso no que tange às políticas públicas.

O Direito transcende à perspectiva normativa, perpassando conteúdos como a sociologia, a política, a economia, dentre outros e as suas diversas vertentes. Sob pena de incorrer em uma perspectiva universalizante e "inocente", conforme denuncia Luciano Oliveira (2004, p. 137), deve-se afirmar que a análise realizada se limita à análise dos estudos de Marcel Maussno tocante às dádivas e José Murilo de Carvalho no que tange à sequência de implementação de direitos no exterior e no Brasil.

O presente tópico visa avaliar os direitos sociais no que tange (1) a falsa noção de concessões do Estado na prestação de benefícios coletivos; (2) efetividade dos direitos sociais quanto à participação cidadã.

3.1 Direitos como dádivas? A relação imaginária de que direitos são relações obrigacionais dar/receber/aceitar entre o indivíduo e o Estado

$\mathrm{Na}$ antropologia, no Ensaio sobre a dádiva: forma e razão da troca nas sociedades arcaicas, a teoria da dádiva de MarcellMauss (2003) elucida que há um sistema de reciprocidades de caráter interpessoal que é universal. A teoria preza pelo caráter simbólico da relação, que é superior ao valor da coisa (Martins, 2005).

A teoria da dádiva não se confunde com as noções de caridade e bênçãos ligadas ao fenômeno religioso como se pode erroneamente inferir. As dádivas são um sistema que se expande ou se retrai a partir das obrigações de dar/receber/devolver bens simbólicos e materiais. A moeda de troca, na aplicação da teoria da dádiva nos direitos sociais, é a subserviência e a espera messiânica de novos direitos, havendo fuga do cidadão comum ao embate no espaço público. 
Explicando o conceito em forma de verbete, para esclarecer a circularidade, Ana Luísa Sertã e Rosana Almeida (2006) apontam que

\begin{abstract}
"as noções de honra e prestígio perpassam a economia da dádiva, sendo essenciais para garantir a circularidade e reversibilidade das trocas. Ao realizar uma prestação, o grupo doador ocupa momentaneamente uma posição superior em relação ao donatário, cumprindo a primeira obrigação de dádiva e estabelecendo uma dívida. Além do eventual rompimento de alianças, recusar o bem ofertado significa reconhecer uma posição inferior em relação ao doador e admitir a incapacidade de retribuir à altura o que lhe foi dado (noção de crédito presente no sistema da dádiva). Visando inverter ou restabelecer hierarquias entre os grupos, o donatário deve oferecer uma contraprestação superior ou equivalente ao que foi recebido, cumprindo a obrigação de retribuir".
\end{abstract}

Uma das perspectivas positivas da teoria é a observância de aspectos alheios à relação puramente obrigacional mercantil como a espontaneidade, a liberdade, a amizade, a criatividade. Para o autor, as relações humanas não se resumem à vínculos de interesse na permuta, numa perspectiva utilitarista, mas os vínculos de comunidade (Santos, 2000, p. 75), traçando esfera distinta do mercado.

Os direitos prestacionais que envolvem o Estado, notadamente sociais, não são dádivas.

A relação se perfaz, numa continuidade, em que há circularidade, onde há agregação de valor ao bem em cada doação. A circularidade e a reciprocidade, em termos de comunidade, é fator a ser valorizado e prestigiado. Todavia, no espaço público multicultural, com pluralidade de opiniões e valores, a impessoalidade e a moralidade administrativa devem imperar.

Muito embora o sistema do associativismo em que o ciclo das dádivas representam numa sociedade seja benéfico na sociedade civil, no âmbito do Estado, essa relação pode ocasionar dependência mútua, subserviência e ineficiência de direitos.

Conforme pontua José Murilo de Carvalho (2018, p. 223), o papel dos legisladores reduz-se, para a maioria dos votantes, ao de intermediarem favores pessoais perante o Executivo. O eleitor vota em troca de promessas de favores pessoais; o deputado apoia o governo em troca de cargos e verbas para distribuir entre seus eleitores. Cria-se 
uma esquizofrenia política: os eleitores desprezam os políticos, mas continuam votando neles na esperança de benefícios pessoais.

A relação eminentemente política faz com que seja constante de um sistema de lutas sociais para o reconhecimento de novas demandas. Conforme Ihering, "o fim do direito é a paz, o meio de que se serve para consegui-lo é a luta" (2002, p. 27). Nesse mesmo sentido, Fabio Konder Komparato afirma que a historicidade dos direitos humanos denuncia a necessidade constante de reafirmação.

A presença forte de sistemas de dádiva não democráticos nas sociedades do Sul e que são fundamentais para a existência dos sistemas familiares e políticos de bases patriarcais ou paternalistas. A relação de dávidas na esfera pública gera corrupção e patrimonialismo (Leal, 2012, p. 222; Holanda, 2014, p. 169) dado que cria supostas relações de hierarquia entre o Estado e os particulares. A concessão de direitos é fruto de disputas políticas, da argumentação com propostas totais e razoáveis. Cria-se de um imaginário de ampliação do ciclo pessoal, numa visão de Estado paternalista, de que o indivíduo encontra, nas assimetrias das relações privadas, o amparo estatal.

Por esse imaginário, segundo Sérgio Buarque de Holanda (p. 175), há uma dificuldade de os detentores das posições públicas de responsabilidade distinguirem entre os domínios privado e público, sendo a máquina pública uma extensão da casa.

Contra essa visão crítica do brasileiro, Jessé Souza, em A Elite do Atraso (p. 73) aponta que essa visão sociológica incontestável que subjuga o brasileiro a padrões morais mais baixos - num princípio de elitismo europeu e de subcidadania local - é um falso argumento científico para perpetuação do escravismo por uma elite econômica (p. 129). O autor ainda aponta que há uma violência simbólica e criminalização do brasileiro, que impede superar o antigo debate como uma narrativa insuperável para dominação ${ }^{8}$. Em que pese as críticas, o autor não aborda diretamente a relação do brasileiro com a reivindicação de direitos, o que impede o diálogo neste particular.

\footnotetext{
${ }^{8}$ Deve-se notar que muitas das críticas do autor são direcionadas a Operação Lava Jato, que visou a moralidade na política.
} 
3.2 Direitos sociais e efetividade constitucional: razão política

A tese de dirigismo constitucional, de inspiração de Joaquim José Gomes Canotilho (2005, p. 50), inspirando o constituinte de 1987 - 1988, somente teve permeabilidade na doutrina acadêmica do Direito Constitucional brasileiro. Contudo, a formação dos blocos supranacionais (em especial a União Europeia) e a crise do Welfare State modificou o cenário jurídico, embora sem respaldo no anseio social, diminui a responsabilidade do Estado na prestação de serviços públicos, ora delegando a atividade a terceiros, ora transformando em atividade econômica a ser explorada pelo Mercado.

A temática da fragilidade dos direitos sociais estão imbricamente ligados à tema do constitucionalismo latino-americano,isso porque os países da América Latina - pelo subdesenvolvimento - encontram-se mais vulneráveis às modificações econômicas da globalização, impactando desproporcionalmente em políticas públicas de redistribuição.

Roberto Gargarela (2009, p. 42), em uma análise dos “200 anos de constitucionalismo latino-americano"exemplifica as práticas do neoliberalismo que levaram à crise social, quais sejam: (1) a Emenda Constitucional 19/98 impulsionada por FHC para o processo privatizador; (2) o tratamento colombiano de intocável para os investimentos estrangeiros; (3) a eliminação dos compromissos sociais no Peru; (4) as garantias argentinas do valor da moeda eliminada.

A revisão de projetos e ordenamentos jurídicos em face da realidade é um projeto da pós-modernidade. Urge a criação de institutos mais adequados para satisfazer as demandas de um mundo cada vez mais virtual e fluido, contrariando o sistema estático. Entretanto, em matéria de implementação de direitos sociais, há sempre desconfiança em sua modificação pela frequente diminuição.

Um exemplo disso é a fixação de jornadas, direito de segunda geração que estipula horário estátil de disposição do empregado ao empregador. Estipular limites cada vez menores - de subordinação de indivíduos é necessário à convivência humana. Todavia, nas sociedades pós-modernas, cujas demandas de flexibilidade e deslocamento são maiores, o controle de ponto se torna dispensável em diversos casos, notadamente nas 
atividades de produtividade intelectual. Por outro lado, a disposição desregrada levaria a abusos na relação. É preciso repensar os institutos jurídicos.

Conforme Dimitri Dimoulis e Leonardo Martins, a divisão de geração de direitos de Karl Vasakem Conferência proferida em 1979 torna-se questionável pela modificação dos direitos (DIMOULIS, 2012, P. 54). A erosãoda distinção entre os direitos liberais clássicos e os direitos sociais é cada vez mais frequente, posto que o Estado, numa ótica neoliberal, posiciona-se como um agente estratégico regulador. A premente necessidade em infraestrutura e mobilidade urbana nos grandes centros são indicativos que os clássicos direitos de $1^{\mathrm{a}}$ geração adquirem contornos jurídicos distintos ao longo do tempo e que, no atual estágio, recorrem ao Estado no papel fundamental de garantir um direito clássico, no caso, a locomoção.

Outro exemplo são os direitos políticos, notadamente o que tange ao sufrágio. A democracia sempre implicou em custos organizacionais. A expansão do voto acelerou os custos do processo eleitoral e tornou-o mais moroso. Todavia, o preço da democracia é um valor dos mais caros a sociedade, do qual não se pode furtar. Assim também são os direitos prestacionais, numa lógica de solidariedade, a redução das desigualdades (objetivo fundamental da República Federativa do Brasil no art. $3^{\circ}$, III da Constituição Federal) é o caminho progressista a ser trilhado pela sociedade de forma racionalizada e estratégica.

Nessa ordem de mudança, segundo Dalmau (2018, p. 45), as Constituições do novo constitucionalismo latino-americano são diplomas normativos e emancipatórios que melhoraram as condições de vida das pessoas, mas falham no seu objetivo de limitar constitucionalmente o poder.

Numa perspectiva tradicional, José Murilo de Carvalho, em A Cidadania no Brasil, aponta que as razões para a ausência de emancipação do indivíduo e fortalecimento do poder se origina da inversão cronológica e lógica da sequência clássica de Marshall de direitos liberais (civis e políticos), direitos sociais e,

"aqui, primeiro vieram os direitos sociais, implantados em período de supressão dos direitos políticos e de redução dos direitos civis por um ditador que se tornou popular. Depois vieram os direitos políticos, de maneira também bizarra. A maior 
expansão do direito do voto deu-se em outro período ditatorial, em que os órgãos de representação política foram transformados em peça decorativa do regime. Finalmente, ainda hoje muitos direitos civis, a base da sequência de Marshal, continuam inacessíveis à maioria da população."

A garantia de direitos aliada a um sistema de freios e contrapesos fraco gera como resultados: (a) baixa efetividade de direitos no plano social, posto que, embora previstos, a prestação é insuficiente como é o caso da saúde e da educação no Brasil; (b) ausência de cultura constitucional (VERDU, 2005, p. 3; SILVA NETO, 2016, p. 1999); (c) baixa participação do indivíduo na esfera pública a fim de fomentar propostas em torno da vida em comum.

Nessa esteira de garantia de direitos numa sociedade de baixa consciência democrática, para amenizar a disparidade no que tange à renda, as Funções Essenciais à Justiça ingressam com ações no Poder Judiciário para promover um desenvolvimento social. Todavia, muitas vezes, a própria população encontra-se alheia à discussão, não conhecendo seus direitos básicos ou podendo opinar nos direitos a serem efetivados.

\section{Controle Jurisdicional de Políticas Públicas}

A crença messiânica enraizada na América Latina resulta num hiperpresidencialismo, em que a principal figura é o chefe do Poder Executivo, em detrimento do espaço deliberativo do Congresso Nacional. Todavia, como o Executivo não consegue se encarregar de todas as carências, as funções essenciais à justiça - e, por conseguinte, o Poder Judiciário - passou a tutelar todas as demandas da sociedade.

Ao passo que haja a efetivação judicial de direitos, deve-se aumentar a consciência cidadã da criação e dos custos dos direitos. A mera tutela judicial sem uma consciência da população mais carente gera assimetrias de informação e descrença no papel dos juízes.

\footnotetext{
${ }^{9}$ Para o autor, o "constitucionalismo tardio é o fenômeno decorrente de causas históricas, políticas e jurídicas, entre outras, da ausência de cultura constitucional nos Estados pós-modernos que são organizados formalmente por meio de uma constituição, o que conduz à ineficácia social dos textos constitucionais"
} 
A ausência de participação democrática resultante do esvaziamento do espaço público tradicional implica na busca do Poder Judiciário para resolução de demandas. Não que os juízes não exerçam funções políticas e não haja o esforço para democratização do Poder Judiciário (como amicus curiae, audiências públicas, ações civis públicas), mas a construção do senso de sujeito de direito nesse espaço assume uma perspectiva dicotômica (procedência/improcedência) muitas vezes de teses já consagradas.

Ainda assim, a postura no processo judicial é de reconhecimento de direitos de forma unilateral mitigada pelo contraditório e ampla defesa (o juiz decide conforme o ordenamento jurídico não podendo os indivíduos criarem novas situações jurídicas numa perspectiva positivista).

Em defesa dos direitos sociais tutelados pelo Poder Judiciário, Andreas Krell observa que as teorias alemãs no que tange ao assunto não podem ser transportadas acriticamente para a realidade brasileira. Segundo o autor, "afirmam que - seguindo a 'linha alemã' - seria teoricamente impossível construir direitos públicos subjetivos a partir de direitos sociais e que o Poder Judiciário não estaria legitimado para tomar decisões sobre determinados benefícios individuais." Ressalta que os autores germânicos não conhecem a realidade local de um Estado em crise e exclusão social.

Na leitura de Marcos Sampaio sobre a obra daquele autor (2013, p. 89), a maior parte da doutrina atribua precipuamente "ao legislativo do papel de conformação dos direitos fundamentais sociais, até os mais conservadores aceitam e defendem a intervenção do Estado social para garantir a existência física da pessoa, ou 'o mínimo social'”.

Em posição diametralmente oposta, contrariando o caráter democrático das propostas doutrinárias de aumento do Poder Judiciário na concretização de direitos sociais, Elival da Silva Ramos (2007, p. 351) salienta que o próprio constituinte condicionou a fruição dos direitos sociais em normas programáticas diretas e derivadas, salientando que não é a doutrina que tem prevalecido no direito estrangeiro e incentiva uma exacerbação do ativismo judiciário. $\mathrm{O}$ autor condiciona a existência de direitos sociais ao grau de desenvolvimento econômico do Estado, posto que pode gerar numa 
desorganização financeiro-orçamentária e que seria o legislador, através da concretização do diploma magno, a quem caberia regulamentar os dispositivos constitucionais.

Em postura intermediária, Felipe Derbli apresenta o impasse: entre a cessão dos atos econômicos transnacionais, perdendo soberania, ou se fecha às pressões, gerando diminuição de receitas e aumento da dívida social (2007, p. 23).

Contrário ou favorável a intervenção do Poder Judiciário, as opiniões congregam a um ponto em comum: mostra-se indispensável a consolidação da democracia no Brasil, seja através do Judiciário seja pelas instâncias tipicamente políticas. Tal debate tecnicista restringe-se aos bancos acadêmicos e ocupa o espaço deliberativo das escolhas racionais da sociedade, principal destinatário das políticas públicas.

Em sentido similar, Felipe Derbli pontua que a modificação do espaço decisório do Estado aos conglomerados empresariais, os conflitos devem ser mediados, havendo inegavelmente a fragilização do poder político, "atingindo um dos pilares fundamentais do Estado de Direito: a democracia representativa.” (2007, p. 39).

Nesse particular, não é possível apontar teses restritivas da participação popular como o caráter contramajoritário do Supremo Tribunal Federal (Waldron, 1999, p. 1043) considerado o beneficiário da política pública. Alijar o povo das escolhas alocativas parece retomar uma perspectiva elitista de democracia, retirando-lhe autonomia.

Se tomarmos como exemplo os julgados acerca da concessão de medicamentos de alto custo no Superior Tribunal de Justiça ${ }^{10}$ e pelo Supremo Tribunal Federal ${ }^{11}$, que deveriam ser debatidos no Congresso Nacional, com ampla participação popular.

\section{Conclusão}

\footnotetext{
${ }^{10}$ A concessão dos medicamentos não incorporados em atos normativos do SUS exige a presença cumulativa dos seguintes requisitos:

(I) comprovação, por meio de laudo médico fundamentado e circunstanciado expedido por médico que assiste o paciente, da imprescindibilidade ou necessidade do medicamento, assim como da ineficácia, para o tratamento da moléstia, dos fármacos fornecidos pelo SUS;

(II) incapacidade financeira de arcar com o custo do medicamento prescrito; e

(III) existência de registro na ANVISA do medicamento.

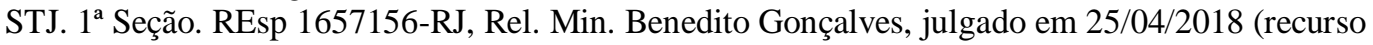
repetitivo) (Informativo 625).

${ }^{11}$ RE - RG 566.471 e 657.718 do Supremo Tribunal Federal, com votação suspensa.
} 
Há uma conexão histórica do déficit de implementação dos direitos sociais no Brasil, da notação elitista de democracia, que gera um hiperpresidencialismo, e a ausência de participação do cidadão na esfera pública. Com o sistema político de subserviência dos cidadãos ao aparato estatal, as relações são propícias à corrupção e ao desmotivo ao ingresso no Estado, muito embora o aparato jurídico seja maximalista e que fomente a participação popular. Ademais, foi possível concluir:

a) O maximalismo democrático foi a corrente adotada pela Constituição Federal de 1988 no que tange à participação política. Tal posicionamento implica em considerarmos, em termos de direitos sociais, um Estado Constitucional Inclusivo, notadamente quanto aos mais necessitados;

b) Há uma tendência de perceber os direitos sociais como dádivas atribuídas pelo Estado. A teoria associativista de Mauss é positiva no tocante à vida comunitária, mas quando transplantada ao Estado corrobora para corrupção e patrimonialismo;

c) A inversão da lógica de Marshall, conforme José Murilo de Carvalho, implicou em uma baixa efetividade dos direitos sociais e em ausência de participação do povo na esfera pública;

d) Nas sociedades pós-modernas, não há que se falar na distinção entre os direitos civis e políticos e os direitos sociais no que tange à participação estatal, posto que ambos a exigem em graus similares.

e) Direitos sociais são direitos sindicáveis, não sendo condicionáveis. É da natureza cidadã das escolhas em implementação em direitos sociais, não se traduzindo em normas meramente programáticas, sem responsabilidade para atribuição estatal;

f) A baixa consciência cidadã corrobora para pleitear em instâncias distintas das democráticas (Executivo e Judiciário) na busca do Poder Judiciário, notadamente através das Funções Essenciais à Justiça;

g) Nas causas que mais envolvem o interesse popular - essencialmente majoritárias -, os cidadãos deveriam fazer frente aos conglomerados econômicos e às pressões da globalização; 


\section{Referências bibliográficas}

ABRANCHES, Sergio. Presidencialismo de coalizão. Raízes e evolução do modelo político brasileiro. São Paulo: Companhia das Letras, 2018.

ADORNO, Theodor. Educação após Auschwitz. In https://rizomas.net/arquivos/Adorno-Educacao-apos-Auschwitz.pdf. Acesso em 6 Nov 2018.

ARGUELHES, Diego Werneck; RIBEIRO, Leandro Molhano.MINISTROCRACIA : O Supremo Tribunal individual e o processo democrático brasileiro. Novos estud. CEBRAP [online]. 2018, vol.37, n.1, pp.13-32. ISSN 01013300. http://dx.doi.org/10.25091/s01013300201800010003.

BARREIROS NETO, Jaime. A Engenharia institucional e o debate contemporâneo da reforma política no Brasil: análise crítica das propostas e tendências. 2017. Tese (Doutorado em Ciências Sociais) - Faculdade de Filosofia e Ciências Humanas, Universidade Federal da Bahia, Salvador.

CARVALHO, José Murillo de. Cidadania no Brasil: o longo caminho. $24^{a}$ Ed. São Paulo: Civilização Brasileira, 2018.

CUNHA JUNIOR, Dirley da. O Estado Constitucional Inclusivo e os desafios da efetividade dos direitos fundamentais sociais. In CUNHA JUNIOR, Dirley da.

BORGES, Lázaro Alves. O Estado Constitucional Inclusivo e os desafios da Modernidade. Salvador, Paginae, 2017.

DALMAU, Rúben Martinez. AS CONSTITUIÇÕES DO NOVO CONSTITUCIONALISMO LATINOAMERICANO FUNCIONARAM?.Revista Culturas Jurídicas, Vol. 5, Núm. 12, set./dez., 2018

FRASER, Nancy. Repensando la esfera pública: una contribuición a la crítica de la democracia actualmente existente. Disponível em

https://estudios.sernam.cl/img/upoloads/fraser_esfera_publica.pdf. Acesso em $20 \mathrm{Dez}$ 2018.

HOLANDA, Cristina Buarque de. Teoria das Elites. $1^{\text {a }}$ Ed. Rio de Janeiro: Zahar, 2001.

HONNETH, Axel. Luta por reconhecimento: a gramática moral dos conflitos sociais.

$2^{a}$ Ed. São Paulo: Editora 34, 2009.

IHERING, Rudolf Von. A Luta Pelo Direito. São Paulo: ed. Martin Claret, 2002. MARTINS, Paulo Henrique (2004b), "Etat, don et revenu de citoyenneté", Revue du MAUSS: de la reconnnaissance. Don, identité et estime de soi, $\mathrm{n}^{\circ} 23$.

MARTINS, Paulo Henrique. «A sociologia de Marcel Mauss: Dádiva, simbolismo e associação », Revista Crítica de Ciências Sociais [Online], 73 | 2005, colocado online no dia 01 outubro 2012, criado a 28 março 2019. URL : http://journals.openedition.org/rccs/954 ; DOI : 10.4000/rccs.954

MAUSS, Marcel. Sociologia e antropologia. São Paulo: Cosac \&Naify, 2003, MAUSS, Marcel; Hubert, Henri. Sobre o sacrifício. São Paulo: Cosac \&Naify, 2005. OLIVEIRA, Luciano. Não fale do código de Hamurábi! A pesquisa sociojurídica na pós-graduação em Direito. In: OLIVEIRA, Luciano. Sua Excelência o Comissário e outros ensaios de Sociologia jurídica. Rio de Janeiro: Letra Legal, 2004, pp. 137-167. PERISSINOTTO, Renato. As elites políticas: questões de teoria e método. $1^{\text {a }} \mathrm{Ed}$. Curitiba: Ibpex, 2009. 
RAMOS, Elival da Silva. "CONTROLE JURISDICIONAL DE POLÍTICAS

PÚBLICAS: a efetivação dos direitos sociais à luz da Constituição brasileira de 1988".

Revista da Faculdade de Direito da Universidade de São Paulo v. 102 p. 327 - 356

jan./dez. 2007 Website: http://www.egov.ufsc.br/portal/sites/default/files/67758-891881 -pb.pdf

SANTOS, Boaventura de Sousa. A crítica da razão indolente: contra o desperdício da experiência. São Paulo: Cortêz Editora, 2000.

SERTÃ, Ana Luísa \& ALMEIDA, Sabrina. 2016. "Ensaio sobre a dádiva".

In: Enciclopédia de Antropologia. São Paulo: Universidade de São Paulo,

Departamento de Antropologia. Disponível em: <http://ea.fflch.usp.br/obra/ensaio-

sobre-dádiva>

SILVA NETO, Manoel Jorge. O constitucionalismo brasileiro tardio. Brasília:

ESMPU, 2016. Disponível em: https://escola.mpu.mp.br/publicacoes/obras- avulsas/e-

books/oconstitucionalismo-brasileirotardio/@@download/arquivo/O\%20Cons

titucionalismo\%20Brasileiro\%20Tardio.pdf.

SOUZA, Jessé. Subcidadania brasileira: para entender o país além do jeitinho brasileiro. São Paulo: Leya, 2018.

VERDÚ, Pablo Lucas. O sentimento constitucional: aproximação ao estudo do sentir constitucional como de integração política. Tradução de Agassiz de Almeida Filho. Rio de Janeiro: Forense, 2004.

VIEIRA, Oscar Vilhena. Supremocracia. Revista Direito GV.[S.1.], v. 4, n. 2, p. 441463, jul. 2008. ISSN 2317-6172. Disponível em:

http://www.scielo.br/pdf/rdgv/v4n2/a05v4n2.pdf. Acesso em 20 Dez 2018.

VILHENA, Oscar Vieira. A batalha dos poderes. São Paulo: Companhia das Letras, 2018.

WALDRON, Jeremy. Law and disagreement. Oxford: Oxford University Press, 1999. 